\title{
The effect of different polishing systems on the surface roughness of a nanocomposite and a microhybrid composite.
}

SADJ July 2017, Vol 72 no 6 p249 - p257

D Kritzinger, ${ }^{1}$ PD Brandt, ${ }^{2}$ FA De Wet. $^{3}$

\section{INTRODUCTION}

The surface smoothness of composite restorations is of great importance in the ultimate success and longevity of restorations. ${ }^{1}$ Surface roughness has an influence on the amount of plaque accumulation on composite surfaces. ${ }^{2}$ A surface roughness threshold of below $0,2 \mu \mathrm{m}$ is necessary to prevent bacterial adhesion and plaque accumulation, ${ }^{3}$ which can cause secondary caries and subsequent failure of the composite restoration. ${ }^{4,5}$ Surface texture also plays an important part in the aesthetics of the restoration. ${ }^{1}$ A rough composite restoration is more prone to discolouration and may be unacceptable to patients as they can detect a surface roughness greater than $0.50 \mu \mathrm{m}$ with their tongues. ${ }^{6,7}$

Most composite restorations require finishing after placement in order to remove overhangs and excess composite material as well as restoring the occlusion and morphology. ${ }^{8}$ The finishing process, however, increases the surface roughness above the acceptable threshold. ${ }^{8}$ Polishing is therefore needed to reduce the surface roughness to acceptable values. ${ }^{2}$

Finishing of a restoration is defined as the gross reduction of excess material to achieve the ideal morphology and

1. Dorette Kritzinger: BMedSc (Stell), BChD (Stell), PGDipDent (Pret), MSc(Dent)(Pret). Department of Odontology, University of Pretoria.

2. Paul D Brandt: $B C h D$ (Stell), MSc(Odont) (Pret), Adv Dip (Aesthetic Medicine) (FDP). Department of Odontology, University of Pretoria.

3. Francois A De Wet: BChD Hons (Pret), MDent (Pret), DTO (Pret), DSc Odont (Pret). Department of Odontology, University of Pretoria.

\section{Corresponding author}

Dorette Kritzinger:

Department of Odontology, University of Pretoria. PO Box 1266 ,

Pretoria, 0001. Tel: 012319 2930. E-mail: Dorette.Kritzinger@up.ac.za optimal function. It is achieved by using either fine and extra-fine diamond burs, or multifluted tungsten carbide burs. ${ }^{1,3,8}$ Polishing of a composite restoration is defined as the reduction of roughness and scratches which were created whilst finishing the composite. ${ }^{8}$

There are different types of polishing abrasive systems: aluminium oxide, carbide compounds, diamond abrasives, silicon dioxide, zirconium oxide and zirconium silicate. $^{3}$ Polishing can also be achieved by using different instruments: coated abrasive discs and strips, stones, aluminium oxide or diamond pastes, soft or hard rubber cups or points, and wheels or brushes impregnated with abrasives.

The manufacturers of composite polishing systems tend to claim excellent polishing results with their systems. ${ }^{8}$ Different factors, however, can influence the effectiveness of any polishing system, for example, the composition of the composite, dissimilarity in hardness between the abrading particles of the polishing system as well as the hardness of the composite, speed with which the abrasive polishing system is applied to the composite and the use of lubricants during the polishing process. $^{3}$ Therefore, different classes of composites, treated with different abrasive systems, will lead to unique surface properties. ${ }^{3}$

Profilometry (surface roughness detection) has been found to be a very good and acceptable method to use in order to study surface roughness of composite samples. ${ }^{4,9}$

\section{AIM AND OBJECTIVES}

The aim of this study was to evaluate and compare the surface roughness of a nanocomposite and a microhybrid composite after they had been polished with different systems. 
The objectives of this study were to:

- Polish two different composites with six different polishing systems.

- Measure the surface roughness for each group.

- Compare the different polishing techniques per composite

- Compare the two composites for polishability.

- Obtain scanning electron microscope (SEM) images of the polished surfaces of one sample per group for evaluation and for comparison with the profilometer readings.

\section{DESIGN}

The study-design for this study was a two-factor (composite and polishing systems) experimental investigation.

\section{METHODS}

Two types of composite were used in this study: a nanocomposite, Filtek Supreme XTE (3M ESPE, St Paul, USA) and a microhybrid composite, Z100 (3M ESPE, St Paul, USA) (Table 1).

Six different polishing methods were tested in this study (Table 2). Thirty-five 2-mm thick composite samples were made from each of the two composites, by placing the uncured composite into ring moulds which had been cut from a $10 \mathrm{~mm}$ diameter aluminium pipe with an ISOMET low speed saw (Buehler Ltd., Lake Bluff, USA).

Mylar polyester strips (Du Pont Co., Wilmington, USA) were placed on both sides of the uncured composite in the ring mould, which was then pressed between two glass plates (each $1 \mathrm{~mm}$ thick) with light finger pressure to extrude the excess material. The composite was cured under a Mylar polyester strip to ensure a standard smooth surface for all samples., 8 Each sample was cured for 40 seconds per side with the tip of the curing light (Valo, Ultradent, South Jordan, USA) being held at right angles in contact with the cover slip and therefore at a $1 \mathrm{~mm}$ distance from the composite surface. The intensity of the curing light was tested at the beginning of each group of samples in order to evaluate curing constancy using a Bluephase radiometer (Ivoclar Vivadent, Schaan, Liechtenstein). After curing the composite samples were removed from the aluminium ring mould. Five of these cured samples were randomly selected to provide a control sample.

After curing, all the samples, except for those of the control group, were finished with a red stripe finishing diamond bur ISO 806314249514012 (Dentsply/ Maillefer, Ballaigues, Switzerland), followed by a yellow stripe finishing diamond bur ISO 806314249504012 (Dentsply/Maillefer, Ballaigues, Switzerland). This was done using a Sirona T4 Racer fast hand piece and Sirona T4 Line B 40 slow hand piece (Sirona Dental, Bensheim, Germany) with copious water spray. In order to mimic the clinical situation, the finishing procedures were completed before polishing of the composite samples. A single operator performed both the finishing and polishing steps to reduce variability.
The 30 remaining finished samples of each composite (Z100 and Filtek Supreme XTE) were randomly allocated to six different polishing groups ( $\mathrm{n}=$ five per group for each composite) and polished according to the manufacturer's instructions for each polishing system, as follows:

Group 1: Mylar Strip : Control Sample

No finishing or polishing was done after the composite had been cured as described above ie. through mylar polyester strips.

Group 2: Sof-Lex XT Finishing and Polishing Discs (3M ESPE, St Paul, USA)

The composite surface was polished using the Sof-Lex XT Finishing and Polishing Discs (coarse, medium $40 \mu \mathrm{m}$, fine $24 \mu \mathrm{m}$ and superfine $8 \mu \mathrm{m})$. The Sof-Lex XT Discs were used sequentially without water coolant in a low-speed handpiece with intermittent light pressure. The coarse-grit disc was used at medium speed (approximately 10000 rpm) for 5 seconds. The disc was then rinsed with water and dried with a 3-in-1 air syringe. Polishing with the medium-grit disc followed, used without water at approximately 10,000 rpm for 15 seconds. The sample was again rinsed and dried. Now the fine grit Sof-Lex XT Disc was used at high speed (approximately 30000 rpm) for 15 seconds. After further rinsing and drying, final polishing of each disc was done using the superfine grit Sof-Lex XT Disc at high speed (approximately 30000 rpm) for 15 seconds. The powder/ debris was washed away with water. ${ }^{14}$

\section{Group 3: Sof-Lex Spiral Finishing and Polishing} Wheels (3M ESPE, St Paul, USA)

The same sequence of polishing using grits of progressively smaller dimensions was followed, interspersed by the routine of washing and drying. The composite surface was first finished with a medium grit Sof-lex XT Polishing Disc, applied at 10000 rpm for 15 seconds. The beige finishing Sof-Lex Spiral Finishing Wheel was then used in a slow handpiece in forward motion with light pressure at a speed between $10000 \mathrm{rpm}-20000 \mathrm{rpm}$ for 15 seconds. The Spiral Wheel was used in constant motion over the composite surface. The composite samples were then polished with the white Sof-Lex Spiral Polishing Wheel, using light pressure at a speed between $10000-$ 20000 rpm for 15 seconds. The surface was finally rinsed with water and dried. ${ }^{13}$

\section{Group 4: Shofu Dura-White Stones (Shofu Inc.,} Kyoto, Japan)

Shofu Dura-White Stones were used in a fast hand piece under copious water spray to polish the composite samples for 10 seconds. ${ }^{15}$ The surface was rinsed with water and dried.

\section{Group 5: Intensiv UniglossCellbrushes (Intensiv SA, Montagnola, Switzerland)}

An Intensiv UniglossCellbrush was initially used dry (without water coolant) with the hard filaments for 15 seconds, under light pressure and low speed (approximately 5000 rpm). Water spray was subsequently added for a few 
seconds whereupon the filaments changed from hard to soft consistency. In order to achieve the final gloss, polishing was done for a further 15 seconds in a wiping motion, with minimal pressure being applied. The surface was rinsed with water and dried. ${ }^{16}$

\section{Group 6: Enhance (Dentsply, Milford, USA)}

An Enhance Finishing Disc, fitted on a slow speed handpiece, was used to apply moderate to light, intermittent pressure in a buffing motion to the dry disc surfaces for 15 seconds at approximately 20000 rpm. Prisma Gloss Polishing Paste, dispersed into a dappen dish and applied in a polishing cup, was used to polish the composite surfaces using light pressure and circular overlapping motions for 15 seconds. A small amount of water was added to the polishing paste and the surfaces were polished with the paste for a further 15 seconds using light pressure at moderate speed (approximately 20 $000 \mathrm{rpm}$ ) in a buffing motion to increase surface lustre. The excess debris and polishing paste were rinsed off with water and the surfaces then dried. ${ }^{17}$
Group 7: Zircon-Brite (Dental Ventures of America, Corona, USA)

After polishing the composite surfaces of the discs as described in Group 3 using the Sof-Lex Spiral Finishing and Polishing Wheels, a further polishing sequel was done using a felt wheel and Zircon-Brite Polishing Paste to polish the composite samples for an additional 10 seconds. ${ }^{19}$

A Surftest SJ 210 profilometer (Mitutoyo, Tokyo, Japan) was used to determine the surface roughness. The composite samples were mounted on a wheel template with three markings: $0^{\circ}, 120^{\circ}$ and $240^{\circ}$. Three readings, in the different directions, were taken on each specimen, resulting in 15 readings per group. The average of the three readings per sample was taken as the average surface roughness value for each sample. After every three readings the profilometer was calibrated using the precision specimen. ${ }^{21}$

After profilometry one sample per group was evaluated in the scanning electron microscope (JEOL JSM-5800 LV, Tokyo, Japan). The samples were investigated and

\begin{tabular}{|c|c|c|c|c|c|c|}
\hline Product & Resin Matrix & Type of Filler & $\begin{array}{l}\text { Mean particle } \\
\text { size }(\mu \mathrm{m})\end{array}$ & $\begin{array}{l}\text { Filler vol. } \\
\%\end{array}$ & Manufacturer & Batch no. \\
\hline Z100 & $\begin{array}{l}\text { Bis-GMA* } \\
\text { TEGDMA§ }\end{array}$ & Zirconia/Silica & 0, 01 to 3,5 micron. & $66 \%$ & $\begin{array}{l}\text { 3M ESPE, } \\
\text { St Paul, USA }\end{array}$ & LOT N585492 \\
\hline $\begin{array}{l}\text { Filtek } \\
\text { Supreme } \\
\text { XTE }\end{array}$ & $\begin{array}{l}\text { Bis-GMA* } \\
\text { UDMA } \\
\text { TEGDMA§ } \\
\text { PEGDMA\# } \\
\text { Bis-EMA† }\end{array}$ & $\begin{array}{l}\text { Non-agglomerated/ } \\
\text { non-aggregated Silica fillers } \\
\text { Non-agglomerated/ } \\
\text { nonaggregated Zirconia filler } \\
\text { Aggregated Zirconia/ Silica } \\
\text { cluster filler }\end{array}$ & $\begin{array}{l}\text { i. } 20 \mathrm{~nm} \text { Silica } \\
\text { ii. } 4 \text { - } 11 \mathrm{~nm} \text { Zirconia } \\
\text { iii. } 0.6-10 \mu \mathrm{m} \\
\text { Zirconia/Silica } \\
\text { clusters }\end{array}$ & $63.3 \%$ & $\begin{array}{l}\text { 3M ESPE, } \\
\text { St Paul, USA }\end{array}$ & LOT N596719 \\
\hline
\end{tabular}

* Bis-GMA: Bisphenol A glycidyl dimethacrylate; § TEGDMA: Triethylene glycal methacrylate;

I UDMA: Urethane dimethacrylate; \# PEGDMA: polyethylene glycol dimethacrylate; †Bis-EMA: Bisphenol A ethyl dimethacrylate

Table 2: Product information about the finishing and polishing systems. ${ }^{13-19}$

\begin{tabular}{|c|c|c|c|c|}
\hline Surface treatment & Type & Composition & Manufacturer & Batch no. \\
\hline $\begin{array}{l}\text { Sof-Lex Extra Thin } \\
\text { Polishing discs } \\
\text { - Coarse (2382C) } \\
\text { - Medium (2382M) } \\
\text { - Fine (2382F) } \\
\text { - Superfine (2382SF) }\end{array}$ & Disc and mandrel & $\begin{array}{l}\text { Polyester film, Aluminium oxide Dif- } \\
\text { ferent grits: } \\
\text { - Coarse: } 55 \mu \mathrm{m} \\
\text { - Medium: } 40 \mu \mathrm{m} \\
\text { - Fine: } 24 \mu \mathrm{m} \\
\text { - Superfine: } 8 \mu \mathrm{m}\end{array}$ & $\begin{array}{l}\text { 3M ESPE, } \\
\text { St Paul, USA }\end{array}$ & $\begin{array}{l}\text { LOT N195023 } \\
\text { LOT N164233 } \\
\text { LOT N411740 } \\
\text { LOT P070516 }\end{array}$ \\
\hline $\begin{array}{l}\text { Sof-Lex Spiral } \\
\text { wheels }\end{array}$ & $\begin{array}{l}\text { Finishing wheel } \\
\text { Polishing wheel }\end{array}$ & $\begin{array}{l}\text { Thermoplastic elastomer } \\
\text { impregnated with aluminium oxide } \\
\text { particles }\end{array}$ & $\begin{array}{l}\text { 3M ESPE, } \\
\text { St Paul, USA }\end{array}$ & $\begin{array}{l}\text { LOT N485117 } \\
\text { LOT N496319 }\end{array}$ \\
\hline Dura White stone & Stone & Aluminium oxide & Shofu Inc., Kyoto, Japan & LOT 0514382 \\
\hline $\begin{array}{l}\text { Intensiv Unigloss } \\
\text { Cellbrush }\end{array}$ & Cellulose brush & Ultrafine diamond particles & $\begin{array}{l}\text { Intensiv SA, } \\
\text { Montagnola, Switzerland }\end{array}$ & LOT 271127 \\
\hline \multirow{2}{*}{ Enhance system } & Finisher discs, points, cups. & $\begin{array}{l}\text { Cured urethane methacrylate resin } \\
\text { impregnated with aluminium oxide }\end{array}$ & \multirow{2}{*}{$\begin{array}{l}\text { Dentsply, } \\
\text { Milford, USA }\end{array}$} & LOT 1106071 \\
\hline & $\begin{array}{l}\text { Prisma Gloss Composite } \\
\text { Polishing paste }\end{array}$ & Water soluble aluminium oxide paste & & LOT 140619 \\
\hline Zircon-Brite & Polishing paste & Zirconium silicate & $\begin{array}{l}\text { Dental Ventures of } \\
\text { America, Corona, USA }\end{array}$ & Not available \\
\hline
\end{tabular}


photographed under $500 \times$ and $1000 \times$ magnification.

Data were analysed using analysis of variance (ANOVA) with the main factors being the composite and the polishing systems.

\section{RESULTS}

\section{Profilometry}

The mean surface roughness values $( \pm S D$ ) for all experimental conditions are presented in Table 3. The average results of the individual polishing procedures, as well as those of the two composites could be combined, as the two composites acted in an almost parallel manner when treated with the individual polishing systems (End-column and end-row in Table 3).

Statistically significant differences were found between the seven experimental groups $(p<0.001)$ (Table 3 - lower case letters). For the combined composite surface roughness values the Mylar strip gave the smoothest finish and was significantly different from the Sof-Lex XT Discs, the Sof-Lex Spiral Finishing and Polishing Wheels and the Sof-Lex Finishing and Polishing Spiral Wheels + Zircon-Brite Polishing Paste, which, in turn, gave a significantly smoother finish than the Intensiv UniglossCellbrush and Enhance + Prisma Gloss Polishing Paste. DuraWhite Stones provided the roughest finish and the resulting surfaces were significantly rougher than in all other groups. These differences are illustrated graphically in Figure 1 where polishing systems under the same black line are not statistically different from each other, while those that do not share a common line are statistically significantly different from each other.

Figure 2 illustrates the different, yet almost parallel, performance by Z100 and Filtek Supreme XTE when polished by the individual polishing systems with Z100 having slightly rougher surfaces after polishing than Filtek Supreme XTE.

\section{Scanning Electron Microscopy}

The Z100 and Filtek Supreme XTE surfaces cured under the Mylar strip appeared quite smooth, but showed small protruding particles and irregularities, possibly polishing debris or small filler particles that protruded from the resin matrix (Figure $3 A$ \& $B$ ). Visually there was no obvious difference in roughness of the surfaces.

The surfaces of the Z100 and the Filtek Supreme XTE samples polished

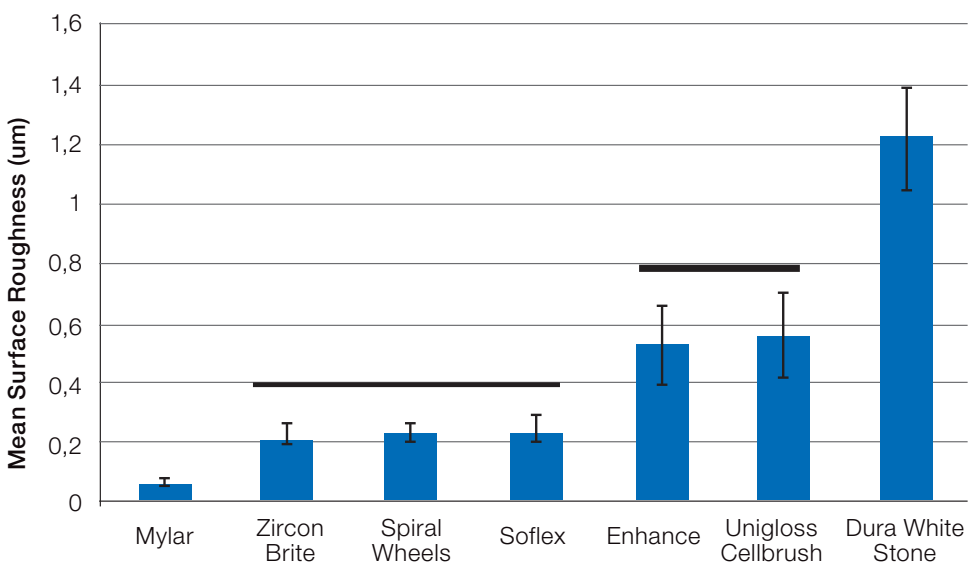

Figure 1: Bar graph of the combined mean composite surface roughnesses (um $\pm \mathrm{SD}$ ) for the polishing systems tested.

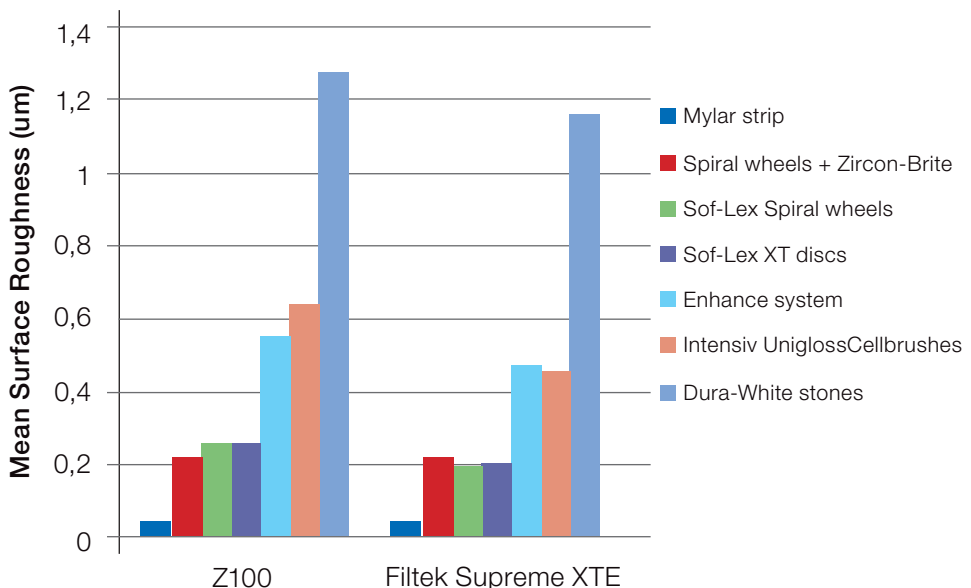

Figure 2: Bar graph of the surface roughness $(\mu \mathrm{m})$ obtained on Z100 and Filtek Supreme XTE with the different polishing systems.
Table 3: Mean surface roughness ( \pm Standard Deviation)( \pm SD) for the two composites and the different polishing systems

Polishing system

omposite mean surface roughness $(\mu \mathrm{m} \pm \mathrm{SD})$

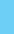

Mylar strip - Control

Sof-Lex discs C, M, F, SF

$\mathrm{Z} 100$

Filtek Supreme

Combined composite mean surface XTE roughness $(\mu \mathrm{m} \pm \mathrm{SD})$

Sof-Lex Spiral wheels $0.059(0.012) \quad 0.050(0.008)$

$0.055(0.11)^{a}$

Dura-White stones

$0.263(0.044)$

$0.211(0.042)$

$0.237(0.049)^{b}$

$0.255(0.027)$

$0.211(0.019)$

$0.233(0.032)^{b}$

Intensiv UniglossCellbrush

$1.284(0.162)$

$1.162(0.183)$

$1.223(0.175)^{d}$

Enhance + PrismaGloss paste

$0.644(0.101)$

$0.473(0.138)$

$0.558(0.145)^{c}$

$0.555(0.183)$

$0.483(0.519)$

$0.519(0.133)^{c}$

Spiral Wheels + Zircon Brite

$0.218(0.047)$

$0.216(0.023)$

$0.217(0.035)^{b}$

Combined polishing system mean surface roughness (in $\mu \mathrm{m}$ )

0.468 (0.399)A

$0.401(0.357) \mathrm{B}$

Different lower case letters indicate statistically significant differences for the combined composite mean surface roughnesses. Uppercase letters indicate statistically significant differences between the two composites for the combined polishing systems mean surface roughnesses. 
with Sof-Lex XT Discs (C, M, F, SF) are shown in Figure 4 $A$ and $B$. Both surfaces were quite smooth with only a few scratch lines and protruding filler/debris particles visible.

The Z100 sample polished with Sof-Lex Spiral Finishing and Polishing Wheels showed a few scratch lines and small voids on the polished surfaces (Figure 5A). Small protruding particles were also noted. The Filtek Supreme XTE sample, in turn, had a relatively smooth surface, with few protruding nano-clusters and smaller filler particles visible (Figure 5B).

The surfaces of both the Z100 and the Filtek Supreme XTE samples polished with Dura-White Stones had a very rough, wavy and uneven appearance, showing clearly visible crests and valleys (Figure 6 A \& B).

The surface of the Z100 sample polished with the Intensiv UniglossCellbrushes had a wavy appearance with clear crests and valleys (Figure 7A) while the surface of the Filtek Supreme XTE sample showed a very wavy, uneven surface, with voids and protruding filler/debris particles visible (Figure 7B).

When Z100 samples were polished with the Enhance system, voids and surface irregularities were visible on the surface, possibly due to the plucking effect of the polishing system (Figure 8A). Protruding filler/debris particles were also visible on the surface. The Filtek Supreme XTE sample, in comparison, showed a wavy appearance, and composite smear lines with protruding filler particles were visible on the surface (Figure 8B).

The surfaces of the Z100 and the Filtek Supreme XTE polished with Sof-Lex Spiral Finishing and Polishing
Wheels followed by Zircon-Brite Polishing Paste are shown in Figure 9 A and B. Both the surfaces for Z100 and Filtek Supreme XTE appeared smooth, with only a few protruding filler/debris particles, and small scratch lines visible.

\section{DISCUSSION}

The composites that were chosen for this study represented two advanced products in composite technology, namely a nano-composite Filtek Supreme XTE, and a more conventional microhybrid composite, Z100. The polishing systems were also carefully chosen, so that most of the major types of polishing systems available on the South African dental market were represented in this study.

Clinically, most composite restorations need to be subjected to some finishing and contouring in order to obtain the correct shape and morphology before polishing. ${ }^{4}$ Therefore, to mimic the clinical situation, all the composite samples were first finished with a red label finishing diamond bur, followed by a yellow label finishing diamond bur. In this study diamond finishing burs were chosen over carbide finishing burs, because the literature demonstrated that carbide burs caused more damage than diamond burs during the finishing procedure, and also that damage which had been caused by diamond burs could more easily be remedied by a good polishing system. ${ }^{9,22}$

The results in this study confirmed that the smoothest composite surface was obtained when the composite was cured against a Mylar strip. These samples were statistically smoother than the roughnesses obtained for any of the other polishing systems tested. Several other studies reported similar findings when curing against a Mylar strip. ${ }^{8,20,23-26}$
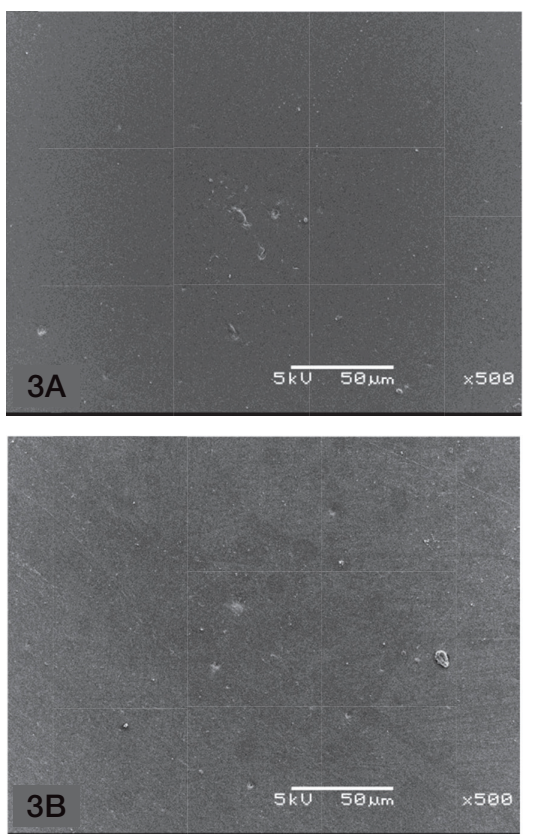

Figure 3: 3A. Z100 and 3B. Filtek Supreme XTE cured under a Mylar polyester strip.
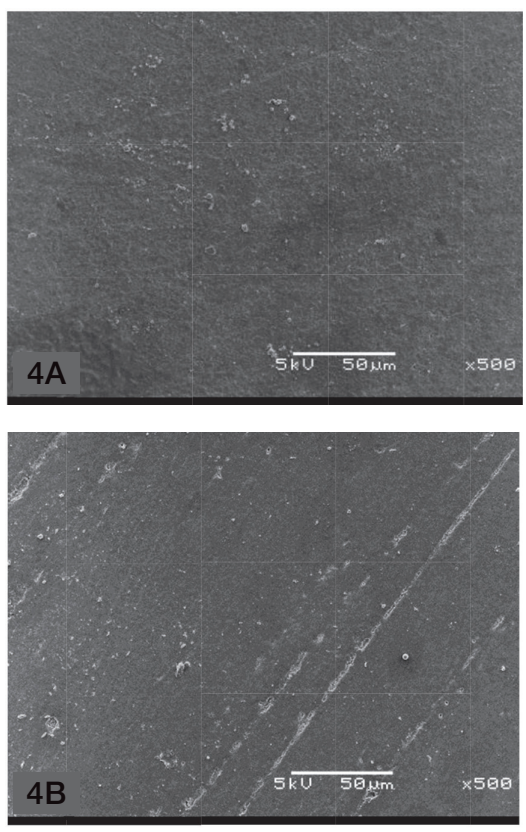

Figure 4: 4A. Z100 and 4B. Filtek Supreme XTE polished with Sof-lex XT discs (C, M, F, SF). (SEM X 500).
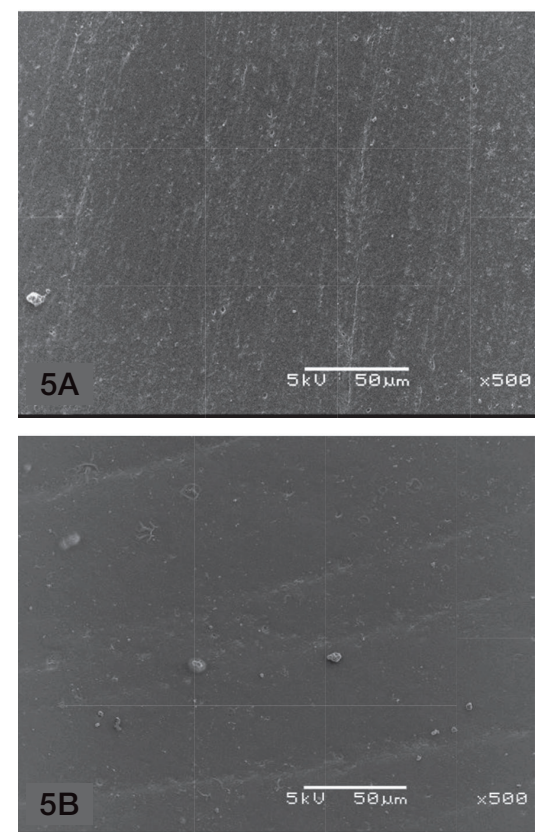

Figure 5: 5A. Z100 and 5B. Filtek Supreme XTE polished with Sof-lex Spiral Wheels. (SEM X 500).

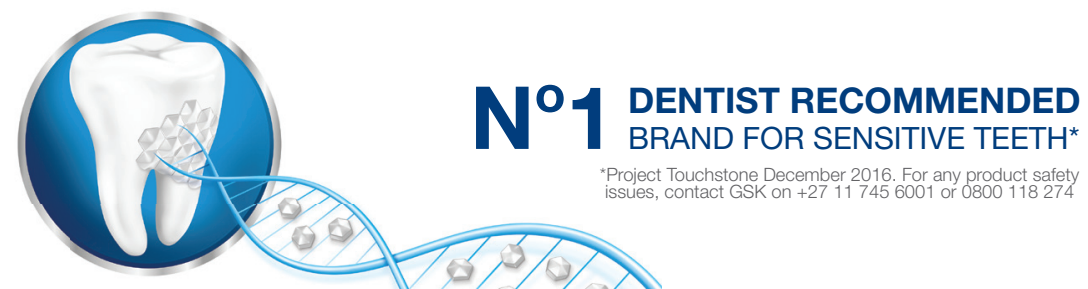



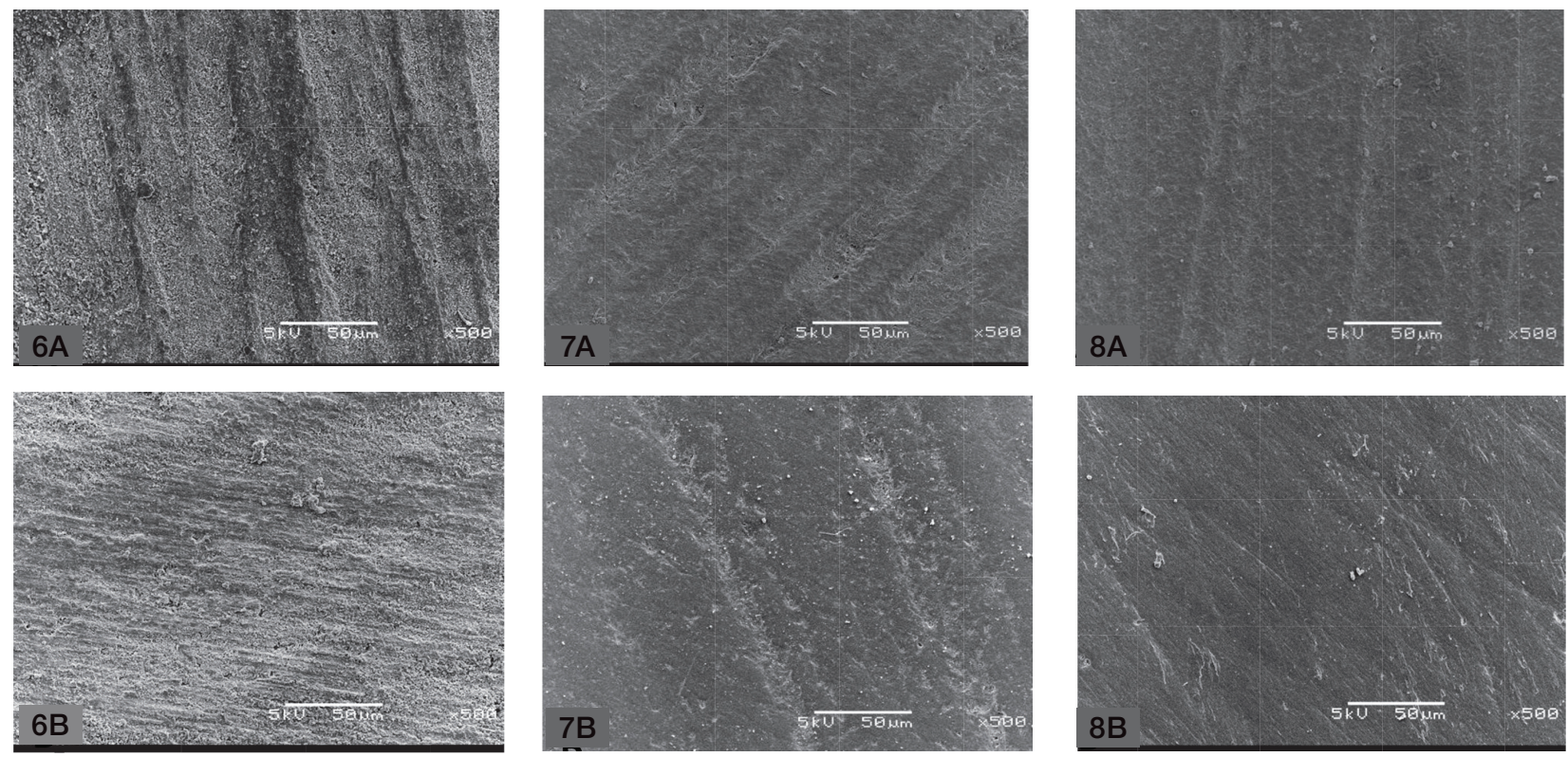

Figure 6: 6A. Z100 and 6B. Filtek Supreme XTE Figure 7: 7A. Z100 and 7B. Filtek Supreme XTE Figure 8: 8A. Z100 and 8B. Filtek Supreme XTE polished with Dura-White Stones (SEM X 500). polished with Intensiv UniglossCellbrush. (SEM X 500). polished with Enhance system. (SEM X 500).

The surface roughness of Z100 before polishing was greater than the surface roughness of Filtek Supreme XTE (Table 3). The lower surface roughness value for Filtek Supreme XTE could be explained by the smaller filler particles (nano particles and clusters of nano-sized fillers) that were incorporated in Filtek Supreme XTE. ${ }^{10}$

After polishing with the different polishing systems, Filtek Supreme XTE had a statistically significant smoother
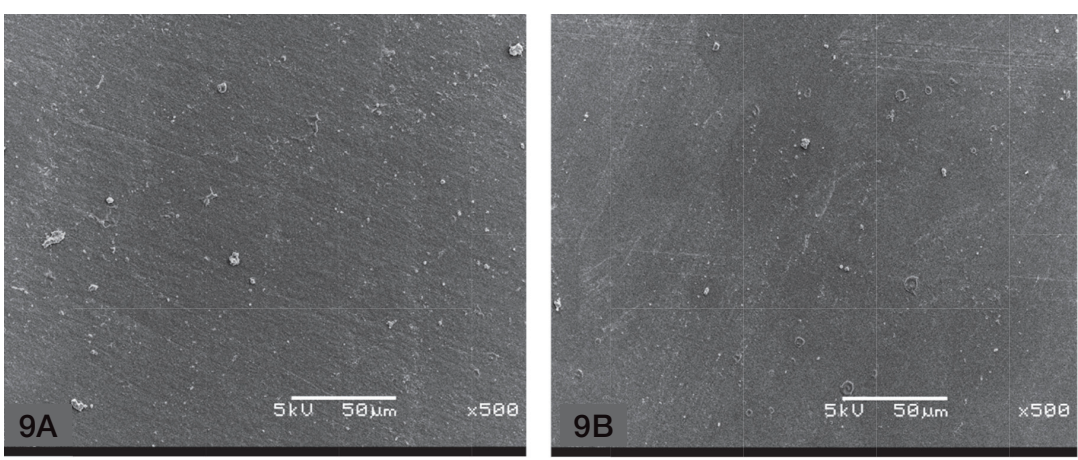
Figure 9: A. Z100 and B. Filtek SupremeXTE polished with Sof-lex Spiral Wheels followed by Zircon-Brite. (SEM X 500). surface when compared with the surface offered by Z100 ( $p=0.005)$. This suggests that Filtek Supreme XTE has better polishability than Z100. This is in accord with a study by Da Costa et al who also demonstrated that Z100 had a statistically significant higher surface roughness value after polishing compared with the surfaces of Filtek Supreme XTE. ${ }^{27}$

The polishing systems acted in a parallel manner on the Z100 and Filtek Supreme XTE, meaning that the polishing systems which recorded results which differed significantly from each other when used on Z100, also differed significantly in results when used on Filtek Supreme XTE. This is in accord with a study by $\mathrm{Da}$ Costa et al who also found no significant interaction between the type of composite used, and the particular polishing system. ${ }^{27}$ Z100 and Filtek Supreme XTE samples displayed surface roughnesses of $1.284 \mu \mathrm{m}$ and $1.162 \mu \mathrm{m}$ respectively after being polished with Dura-White Stone (Table 3). This is above the 0,2 $\mu \mathrm{m}$ threshold for surface roughness allowing for plaque adhesion, and much higher than the $0,5 \mu \mathrm{m}$ that patients can detect with their tongues. ${ }^{2,28}$ Therefore, Dura-White Stone, used on its

own, is not sufficient for the polishing of micro-hybrid and nano-composite restorations.

The following polishing systems provided the smoothest surfaces after polishing: Sof-Lex Spiral Finishing and Polishing Wheels in combination with Zircon-Brite Polishing Paste, as well as the Sof-Lex Spiral Finishing and Polishing Wheels and Sof-Lex XT Finishing and Polishing Discs used without additional pastes. The surfaces prepared by these systems were significantly smoother than those produced by the Enhance method used in combination with Prisma Gloss Polishing Paste, and also by the one-step polishing system, Intensiv UniglossCellbrush. There was no statistically significant difference between the results produced by Sof-Lex Spiral Finishing and Polishing Wheels in combination with Zircon-Brite Polishing Paste, the SofLex Spiral Finishing and Polishing Wheels or the surface roughness after polishing by the Sof-Lex XT Finishing and Polishing Discs. The fact that Sof-Lex XT Finishing and Polishing Discs produced some of the smoothest surfaces after polishing is supported by several other studies. ${ }^{29-31}$ The surface roughness for Z100 after polishing with Sof-Lex Finishing and Polishing Discs was found in in a study by Yap 
and co-workers to be $0.22 \mu \mathrm{m} .{ }^{32}$ This is very close to the value found in the current study, namely $0.26 \mu \mathrm{m}$.

Enhance, in combination with Prisma Gloss Polishing Paste, and the Intensiv UniglossCellbrush did not differ significantly from each other in results produced, but both were over the $0,2 \mu \mathrm{m}$ thresholds for plaque accumulation. The finding, within the confines of this study, that Enhance performed poorly was in accord with a study done by Kaplan and co-workers. ${ }^{33}$

The surface roughness values obtained for all the polishing systems in this study were the lowest when they were used on Filtek Supreme XTE. The finding that the polishing systems gave better results when used on a nanocomposite than on a microhybrid composite is in agreement with a previous study. ${ }^{34}$

The surface roughness values for Sof-Lex Spiral Finishing and Polishing Wheels and also for Sof-Lex XT Finishing and Polishing Discs, when used on Filtek Supreme XTE, were measured as $0.211 \mu \mathrm{m}$. This is below the plaque accumulation threshold and the patient's sensory feeling threshold, rendering these systems appropriate for clinical use.

The smoothest surface for Z100 was obtained with a combination of Sof-Lex Spiral Finishing and Polishing Wheels and Zircon-Brite Polishing Paste. No previous studies have been done where Zircon-Brite was used in combination with Sof-Lex Spiral Finishing and Polishing Wheels. This combination, although proving to create the smoothest surface, was not statistically different compared with the data of the Sof-Lex Spiral Finishing and Polishing Wheels or the Sof-Lex XT Finishing and Polishing Discs groups. When Zircon-Brite Polishing Paste was use on Filtek Supreme XTE there was no difference in final surface roughness compared with Sof-Lex Spiral Finishing and Polishing Wheels. This can be attributed to the nano filler particles of Filtek Supreme XTE.10 The operator found that using Zircon-Brite Polishing Paste in combination with Sof-Lex Spiral Finishing and Polishing Wheels, was time consuming and more costly than just using the Sof-Lex Spiral Finishing and Polishing Wheels alone. Cost efficiency points to the use of Sof-Lex Spiral Finishing and Polishing Wheels alone.

The Sof-Lex XT Finishing and Polishing discs, the Sof-Lex Spiral Finishing and Polishing Wheels, as well as the SofLex Spiral Finishing and Polishing Wheels combined with the Zircon-Brite Polishing Paste showed a lower variability in the final smoothness than the Enhance and Unigloss Cellbrush systems, as well as the Dura-White Stone - as indicated by the standard deviations of each system (Figure 1). Clinically, this may mean that the Sof-Lex XT Finishing and Polishing Discs and the Sof-Lex Spiral Finishing and Polishing Wheels, as well as the Sof-Lex Spiral Finishing and Polishing Wheels combined with the Zircon-Brite Polishing Paste, may provide a less technique-sensitive polishing sequence to the dental operator.

\section{CONCLUSION}

Filtek Supreme XTE, used in this study as an example of a nanocomposite, displayed significantly better polishability than Z100, used in this study as an example of a microhybrid composite. Some polishing systems produced statistically smoother surfaces than others. The smoothest surface was obtained after curing through a Mylar strip. The smoothest surface after polishing was the Zircon-Brite/Spiral Wheel combination, followed by Sof-Lex Spiral Finishing and Polishing Wheels and Sof-Lex XT Finishing and Polishing Discs. These systems did not differ significantly from each other, but did give significantly smoother surfaces than Enhance, Intensiv UniglossCellbrush and Dura-White Stone. The polishing results in this study are true for Z100 and Filtek Supreme XTE and the conclusion about polishing systems is limited to use on Z100 and Filtek Supreme XTE. Further studies using other composite products of the same classification and from across the trade need to be performed as comparison.

\section{Acknowledgements}

The authors give acknowledgement to the Pameijer Fellowship (IADR) and the Dentistry Development Foundation Trust (SADA) which provided financial assistance and to 3M ESPE (St Paul, USA) for sponsoring some of the materials used in this study.

\section{References}

1. Mopper KW. Contouring, finishing, and polishing anterior composites. Inside Dent. 2011;7:62-70.

2. Bollen CM, Lambrechts $\mathrm{P}$, Quirynen M. Comparison of surface roughness of oral hard materials to the threshold surface roughness for bacterial plaque retention: a review of the literature. Dent Mater. 1997;13(4):258-69.

3. Jefferies SR. Abrasive finishing and polishing in restorative dentistry: a state-of-the-art review. Dent Clin North Am. 2007;51(2):379-97.

4. Anusavice KJ, editor. Phillips' Science of Dental Materials. 11th ed. St. Louis, Missouri, USA: Saunders; 2003, pp 351-77.

5. Aykent F, Yondem I, Ozyesil AG, Gunal AS, Avunduk MC, Ozkan S. Effect of different finishing techniques for restorative materials on surface roughness and bacterial adhesion. J Prosthet Dent. 2010;103(4):221-7.

6. Reis AF, Giannini M, Lovadino JR, et al. Effects of various finishing systems on the surface roughness and staining susceptibility of packable composite resins. Dent Mater. 2003;19(1):12-8.

7. Jones $\mathrm{C}$, Billington R, Pearson $\mathrm{G}$. The in vivo perception of roughness of restorations. Br Dent J. 2004;196(1):42-5.

8. Erdemir U, Sancakli HS, Yildiz E. The effect of one-step and multi-step polishing systems on the surface roughness and microhardness of novel resin composites. Eur J Dent. 2012;6(2):198-205.

9. Joniot S, Gregoire G, Auther A, Rooques AM. Threedimensional optical profilometry analysis of surface states obtained after finishing sequences for three composite resins. Oper Dent. 1999;25(4):311-5.

10. FiltekTM Supreme XTE Universal Restorative System technical product profile Filtek Australia \& NZ: 3M ESPE; 2010 [cited 2015 May 6]. Available from: http://multimedia.3m. com/mws/media/6430700/filtek-supreme-xte-technicalprofileanz.pdf.

11. 3M ESPE FiltekTMSupreme XTE Universal Restorative Instructions for use Seefeld, Germany: 3M ESPE; 2010.

12. 3M ESPE Z100TMMP Restorative Instructions for Use. St. 
Paul, MN, USA: 3M ESPE; 2012.

13. 3M ESPE Sof-LexTM Spiral Finishing and Polishing Wheels Instructions for Use. St. Paul, MN, USA: 3M ESPE; 2013.

14. 3M ESPE Sof-LexTM Finishing and Polishing Systems USA: 3M ESPE; 2002 [cited 2015 May 6]. Available from: http:// multimedia.3m.com/mws/media/147543O/soflextm-finishingand-polishing-system.pdf.

15. Dura-White Instructions for Use. Japan: Shofu Inc.

16. Intensiv UniglossCellbrush. Montagnola, Switzerland: Intensiv Swiss Dental Products; 2011.

17. Enhance Finishing and Polishing System Directions for Use. USA: Dentsply International Inc. ; 2004.

18. Prisma.GlossTM Prisma.GlossTMExtra Fine Composite Polishing Pastes Direction for Use. USA: Dentsply International Inc. ; 2010.

19. DVA Zircon-Brite Description and Application: Dental Ventures of America Inc.; [cited 2015 May 6]. Available from: http:// dentalventures.com/zircon-brite/.

20. Attar N. The effect of finishing and polishing procedures on the surface roughness of composite resin materials. J Contemp Dent Pract. 2007;8(1):27-35.

21. Mitutoyo Surftest SJ-210 Surface Roughness Measuring Tester SJ-210 User Manual. Japan: Mitutoyo.

22. Goldstein G, Waknine S. Surface roughness evaluation of composite resin polishing techniques. Quintessence Int. 1989;20(3):199-204.

23. Korkmaz Y, Ozel E, Attar N, Aksoy G. The influence of one-step polishing systems on the surface roughness and microhardness of nanocomposites. Oper Dent. 2008;33(1):44-50.

24. Heath J, Wilson H. Surface roughness of restorations. Br Dent J. 1976;140(4):131.

25. Baseren M. Surface roughness of nanofill and nanohybrid composite resin and ormocerbased tooth-colored restorative materials after several finishing and polishing procedures. J Biomat Applic. 2004;19(2):121-34.

26. De Wet F, Ferreira M. Polishing procedures for microfilled resins. SADJ. 1982;37(12):797-803

27. Da Costa J, Ferracane J, Paravina RD, Mazur RF, Roeder L. The effect of different polishing systems on surface roughness and gloss of various resin composites. J Esthet Restor Dent. 2007;19(4):214-24; discussion 25-6.

28. Quirynen M, Bollen C. The influence of surface roughness and surface free energy on supra and subgingival plaque formation in man. J Clin Periodontol. 1995;22(1):1-14.

29. Antonson SA, Yazici AR, Kilinc E, Antonson DE, Hardigan PC. Comparison of different finishing/polishing systems on surface roughness and gloss of resin composites. J Dent. 2011;39, Supplement 1(0):e9-e17.

30. Koh R, Neiva G, Dennison J, Yaman P. Finishing systems on the final surface roughness of composites. J Contemp Dent Pract. 2008;9(2):138-45.

31. Janus J, Fauxpoint G, Arntz Y, Pelletier H, Etienne O. Surface roughness and morphology of three nanocomposites after two different polishing treatments by a multitechnique approach. Dent Mater. 2010;26(5):416-25.

32. Yap A, Yap S, Teo C, NG JJ. Finishing/polishing of composite and compomer restoratives: Effectiveness of one-step systems. Oper Dent. 2003;29(3):275-9.

33. Kaplan BA, Goldstein GR, Vijayaraghavan T, Nelson IK. The effect of three polishing systems on the surface roughness of four hybrid composites: a profilometric and scanning electron microscopy study. J Prosthet Dent. 1996;76(1):34-8.

34. Senawongse $P$, Pongprueksa $P$. Surface roughness of nanofill and nanohybrid resin composites after polishing and brushing. J Esthet Restor Dent. 2007;19(5):265-73. 